\title{
Avaliação do clima organizacional de suporte à criatividade e inovação em programas de pós-graduação stricto sensu
}

\author{
Evaluation of the organizational climate in support of creativity and innovation \\ in stricto sensu graduate programs
}

\author{
Monique Brandão Comes ${ }^{1}$ \\ Fernando Victor Cavalcante ${ }^{2}$ \\ Favio Akiyoshi Toda ${ }^{3}$
}

\begin{abstract}
Resumo
Este estudo teve como objetivo avaliar a diferença do clima de suporte à criatividade e inovação entre dois programas de pósgraduação de uma reconhecida instituição de ciência e tecnologia em saúde no Brasil, executando uma análise comparativa do clima interno entre um programa de excelência já consolidado e um iniciante. Ambos os programas ministram cursos de mestrado e doutorado. O primeiro, com nota máxima, sete, em seus cursos, e o segundo com nota três em seu curso de mestrado e nota dois no curso de doutorado. Os sujeitos ouvidos para o estudo em cada um dos programas foram o coordenador do curso, o secretário acadêmico, um docente permanente membro da Comissão de Pós-graduação, um docente permanente não membro da CPG, e um docente colaborador. Os sujeitos foram selecionados intencionalmente e por conveniência de disponibilidade para a entrevista, e a coleta de dados ocorreu mediante realização de entrevistas em profundidade para avaliar o clima orientado para criatividade e inovação e o nível de apoio em cada programa. Além das entrevistas, foram avaliadas as Fichas de Avaliação dos Programas provisórias do último quadriênio (2013-2016), que permitiram ampliar a análise entre os programas estudados. Os achados evidenciaram que o clima orientado para criatividade e inovação contribui para explicar a nota de avaliação da Capes. Os resultados do estudo permitiram corroborar estudos anteriores e, em termos práticos, a pesquisa oferta subsídios para o processo de tomada de decisão dentro de programas de pós-graduação stricto sensu.
\end{abstract}

Palavras-chave: Clima organizacional de suporte à criatividade e inovação. Avaliação. Pós-graduação stricto sensu. CAPES.

\begin{abstract}
This study aimed to evaluate the difference in the climate of support for creativity and innovation between two postgraduate programs of a health science and technology institution, performing a comparative analysis of the internal climate between an already consolidated program of excellence and a beginner. Both programs offer masters and doctorate courses, the first with a grade of 7 (seven) in its courses and the second with a grade of 3 (three) in its master's degree and 2 (two) in the doctorate course. The subjects heard for the study in each of the programs were the course coordinator, the academic secretary, a permanent faculty member of the Postgraduate Committee, a permanent non-CPG faculty member, and a teaching staff member. The subjects were selected intentionally and for convenience of availability for the interview, and the data collection took place through in-depth interviews to evaluate the climate oriented to creativity and innovation and the level of support in each program. In addition to the interviews, the Evaluation Papers of the Provisional Programs of the last quadrennium (2013-2016) were evaluated, which allowed to broaden the analysis among the Programs studied. The findings showed that the climate oriented to creativity and innovation contributes to explain Capes'evaluation note. The results of the study allowed to corroborate previous studies and in practical terms, the research offer subsidies for the decision-making process within Stricto Sensu Graduate Programs.
\end{abstract}

Keywords: Organizational climate of support to creativity and innovation. Evaluation. Stricto sensu post-graduation. CAPES.

Mestre em Gestão e Estratégia pela Universidade Federal Rural do Rio de Janeiro (UFRRJ - 2016). Especialista em Gestão Acadêmica pelo Instituto Nacional de Saúde, da Mulher, da Criança e do Adolescente Fernandes Figueira da Fundação Oswaldo Cruz (IFF/ Fiocruz - 2017). Atualmente é Assistente Técnico de Gestão em Saúde na Fundação Oswaldo Cruz. Afiliação: Universidade Federal Rural do Rio de Janeiro. Brasil. Lattes: http://lattes.cnpq.br/0762653810535762 Email: monique.comes@gmail.com

2 Especialização em Gestão de Organizações em C\&T em Saúde pela Escola Nacional de Saúde Pública/Fiocruz, Brasil(2014). Analista de Gestão em Saúde da Fundação Oswaldo Cruz. Brasil. Afiliação: Universidade Federal Rural do Rio de Janeiro. Lattes: http://lattes.cnpq. br/6047091361895162 Email: fervicante@gmail.com

3 Doutorado em Administração de Empresas pela Pontifícia Universidade Católica do Rio de Janeiro, Brasil(2013). Professor adjunto da Universidade Federal Fluminense. Brasil. Afiliação: Universidade Federal Rural do Rio de Janeiro. Lattes: http://lattes.cnpq.br/2064135511749727 Email: favio.toda@uol.com.br 


\section{Introdução}

O panorama da pós-graduação brasileira, segundo dados de 2017 do Geocapes - Sistema de Informações Georreferenciadas da Coordenação de Aperfeiçoamento de Pessoal de Nível Superior (Capes), congregava, até 2016, 4.177 cursos, sendo: 2.106 de mestrado e doutorado; 1.292 apenas de mestrado, 76 apenas de doutorado e 703 de mestrado profissional. Destes, 3.474 cursos acadêmicos, somente 145 são avaliados com a nota 7 (sete), máxima da Capes, equivalente ao alto padrão internacional. A razão entre o número de cursos avaliados pela Capes com nota sete e o número total de cursos acadêmicos, no último quadriênio avaliado (2013-2016), equivale a apenas 4,17\%, observando-se uma queda relacionada ao último triênio (2010-2012), que apresentava uma proporção de 4,39\%.

Os programas de pós-graduação podem obter avaliações da Capes que variam dos graus 1 a 7 . Os conceitos 1 e 2 acarretam descredenciamento, enquanto 3 representa um programa regular. As notas 4 e 5 são aplicadas aos programas que possuem um bom desempenho, sendo a segunda a maior nota que um programa que possua apenas mestrado possa receber. Como limite e equiparando a um padrão internacional, são aplicadas as notas 6 e 7 (CAPES, 2013).

A Capes avalia os programas em cinco grandes blocos: 1 - A proposta do programa (coerência, planejamento e infraestrutura), 2 - Corpo docente (perfil, adequação e dedicação, distribuição das atividades de pesquisa entre os docentes, contribuição dos docentes, e captação de recursos), 3 - Corpo discente, teses e dissertações, 4 - Produção intelectual e 5 - Inserção social.

Para a obtenção de uma avaliação de qualidade, além dos requisitos pré-estabelecidos pela Capes, as informações sobre a produção do programa devem ser preenchidas corretamente em uma plataforma, o que depende do repasse de dados de qualidade pelos docentes para as coordenações e secretarias acadêmicas, através da atualização de seus currículos Lattes. Quando isso não ocorre, a avaliação do programa pode ser substancialmente prejudicada.

As secretarias acadêmicas apresentam um papel importante para organização dos dados que servem de base para as avaliações. Possuem, na maioria dos programas de pós-graduação, o papel de apoiar a coordenação na coleta das informações para a avaliação da Capes. Acompanha-se o processo desde a divulgação do calendário pela Capes, a coleta de informações através dos currículos Lattes, a alimentação da plataforma, até o feedback à coordenação dos resultados individuais por docente e do programa de uma forma coletiva.

Assim, a avaliação de um programa depende do nível de cooperação entre a coordenação, seus professores e a secretaria acadêmica, além do desempenho individual da produção docente e discente. Visto que a colaboração é uma característica que pode ser observada relativa à cultura organizacional (Hurley, 1995), este estudo tem a seguinte pergunta problema: existem fatores do clima organizacional de suporte à criatividade e inovação que estão mais presentes em programas de nota sete do que em programas de notas mais baixas?

O clima organizacional de suporte à criatividade e inovação começou a ser estudado por Siegel e Kaemmerer na década de 70 . Os autores notaram que se trata de um construto que pode ser observado para explicar diferenças entre escolas inovadoras e tradicionais.

Mesmo não tratando diretamente de programas de pós-graduação, mas relacionado com a educação, Fidan e Oztürk (2015) mencionam que professores experientes são capazes de melhor perceber um clima mais favorável em relação ao apoio à inovação e alocação de recursos. Os autores também enfatizaram que a motivação intrínseca e a criatividade são mais evidenciadas em professores que trabalham em escolas privadas do que em públicas e, ainda, que os fatores intrínsecos têm mais efeitos positivos do que os extrínsecos no contexto escolar. "As escolas relativamente menores proporcionam melhores condições e alocam mais recursos para aumentar a capacidade de inovação” (ibidem, p. 913).

Compreender os mecanismos por trás da criatividade dos professores no contexto escolar é uma luta importante, tanto para profissionais de administração quanto para pesquisadores. Escolas como comunidades de aprendizagem profissional são esperadas para albergar e apoiar ideias e esforços inovadores, 
compensando os efeitos externos que dificultam e proporcionando um clima frutífero para a criatividade individual (ibidem, p. 912).

Este estudo tem como suposição que, através de um clima mais colaborativo em um programa de pós-graduação, os seus membros podem vir a desenvolver soluções mais criativas e inovadoras para os problemas que estão relacionados à obtenção de uma avaliação positiva da Capes, incluindo as atividades operacionais relativas à secretaria acadêmica.

O objetivo da pesquisa é avaliar a diferença do clima de suporte à criatividade e inovação entre dois programas: um de nota máxima (7) e um de nota mínima para funcionamento (3). O projeto visa executar uma análise qualitativa dos fatores que caracterizam e distinguem os diferentes tipos de clima nos dois programas. Para melhor compreensão das diferenças entre os programas, faz-se uma análise comparativa entre as fichas de avaliação dos dois programas no último quadriênio (2013-2016). Observou-se, durante este estudo, a abordagem do tema em escolas, frente a uma lacuna e necessidade de aprofundamento em programas de pós-graduação, com destaque para os cursos stricto sensu.

A pesquisa contribui na apresentação de estratégias utilizadas por programas com nota máxima, o que pode ser útil no desenvolvimento de táticas eficazes por parte dos programas que buscam atingir, ou manter, a nota máxima. Tal objetivo, uma vez alcançado, poderá permitir o reconhecimento do programa, assim como o máximo de acesso aos recursos que são disponibilizados.

Com o reconhecimento do curso, o curso de pós-graduação é contemplado através do Programa de Apoio à Pós-graduação - PROAP, em que há o repasse de recursos financeiros de acordo com a nota dos cursos na avaliação mais recente realizada pela Capes (CAPES, 2014) e do Programa de Demanda Social - DS, em que são concedidas bolsas com base nos sistemas de acompanhamento e avaliação (CAPES, 2010). Já os cursos avaliados com conceitos 6 ou 7 fazem jus, ainda, ao Programa de Excelência Acadêmica - PROEX, cujos valores podem ser utilizados através de critérios do próprio programa (CAPES, 2015).

De acordo com o portal da Capes, na avaliação do quadriênio 2013-2016, realizada em 2017, se comparados com avaliações de anos anteriores, $67 \%$ dos programas mantiveram os conceitos obtidos, $22 \%$ aumentaram de grau e em apenas $11 \%$ houve decréscimo, demonstrando uma invariabilidade do sistema (CAPES, 2017).

São interesses de estudo os programas avaliados no último quadriênio (2013-2016) com a nota 7 (sete) pela Capes. Do total de 145, 27 cursos acadêmicos estão localizados na metrópole do Rio de Janeiro. Dessa forma, delimita-se o trabalho de campo a dois programas de pós-graduação da mesma instituição. O primeiro programa selecionado obteve nota 3 (três) em mestrado e 2 (dois) em doutorado (P3). Como critério para a segunda seleção, opta-se por um dos programas avaliados e que manteve a nota 7 (sete) em ambos os cursos (P7), num total de dois da mesma unidade, de acordo com a avaliação provisória do último quadriênio (2013-2016).

Este artigo se estrutura em seis seções, iniciando com esta introdução ao tema. A segunda seção é representada pelo referencial teórico, enquanto a terceira apresenta os procedimentos metodológicos. A quarta e quinta seções apontam os resultados e a discussão, respectivamente. Por fim, a última seção abordará a conclusão da pesquisa.

\section{Referencial Teórico}

\subsection{Gestão universitária e avaliação Capes}

Junior et al. (2011) ressaltam, em relação à aplicação da gestão estratégica, que as universidades podem ser equiparadas às organizações e suas decisões impactam diretamente na área acadêmica e suas estratégias, nas quais encontram seus maiores desafios. Os autores argumentam que as estratégias acadêmicas derivam da consideração de diversos fatores internos e externos, não havendo, portanto, um único caminho a seguir para a conquista de objetivos.

Os coordenadores dos cursos são responsáveis diretos pelas estratégias acadêmicas, que devem estar alinhadas às metas da universidade, ainda que exista certa distância entre a teoria e a prática (JUNIOR 
et al, 2011). Os autores destacam que, no setor acadêmico, muitos cargos de lideranças são ocupados por docentes, e não por membros que ocupem um cargo especializado em gestão, o que pode impactar tanto positivamente quanto negativamente: positivamente, porque o uso de uma linguagem comum aos membros da instituição facilita o processo de legitimação; e negativamente, porque a pessoa não necessariamente possui habilidades no campo da gestão.

Apesar da alimentação da Plataforma Sucupira ser responsabilidade da coordenação, as secretarias atuam como suporte fundamental no processo, verificando os registros acadêmicos e as produções dos docentes e discentes, além de outras atividades do programa (SOARES e PAULY, 2015). Amaral et al. (2017) relacionam uma série de deficiências que podem prejudicar o processo de avaliação, como a inconsistência dos dados alimentados na plataforma e a maneira como são inseridos. Como as informações não estão organizadas, o coordenador as subaproveita para evolução do desempenho do programa.

Amaral et al. (2017) concluem que os indicadores de avaliação da Capes contribuem para a tomada de decisão do coordenador, desde que "as barreiras de conversão e tratamento dos dados possam ser vencidas, por meio da aplicação de ferramentas especialistas para o uso e análise da informação".

Montagner et al. (2009) alertam que a Plataforma Lattes, apesar de ser eficaz na divulgação das informações pertinentes, possui muitos dados incorretos ou incompletos, além de apresentar falta de padronização. Fagá e Quoniam (2016) observaram um número significativo de produções inseridas em parcerias entre docentes e discentes que não constavam nos currículos Lattes dos professores. Ressaltam que a não atualização do currículo pode prejudicar a avaliação do programa perante a Capes, apesar de toda contribuição intelectual.

Em estudo realizado por Maccari et al. (2008) atesta-se que há resistência dos docentes em manter seus currículos atualizados e que os mesmos consideram válido o oferecimento de cursos e seminários que possibilitem o esclarecimento de dúvidas e incorporamento da prática na cultura da organização. Moro et al. (2013) salientam que os docentes possuem inúmeras atividades, principalmente administrativas e relacionadas aos cursos, e estão submetidos a uma sobrecarga de trabalho que pode interferir na sua atuação no programa.

Cooper-Hakim e Viswesvaran (2005) definem o comprometimento com a carreira como dedicação ou compromisso de um indivíduo com sua profissão e, para isso, deve ser reconhecido o sentimento positivo em relação ao cargo.

Souza e Guimarães (2016) recomendam que docentes que atuam nas áreas de extensão e pesquisa devem manter a atualização de seus currículos, devido à exigência dos órgãos de fomento. Além disso, destaca-se que a atualização periódica dos currículos e o conhecimento sobre os critérios da Capes são importantes e podem fazer a diferença para a avaliação do programa de pós-graduação (FAGÁ e QUONIAM, 2016).

A inovação em educação vem ganhando crescente interesse, visto que a qualidade da área é valiosa para as políticas públicas (TODA et al., 2015). O tema será destrinchado na subseção a seguir.

\subsection{Inovação e educação}

Para a OECD (2009), a melhoria das práticas relacionadas aos serviços educacionais pode ser identificada como inovação. Deve-se considerar que a adoção dessa inovação, seja por uma instituição de educação públical, seja privada, pode ser realizada por questões técnicas ou políticas (ESTEVÃO, 1994). O autor destaca que, mesmo que a administração pública em instituições de ensino seja burocrática, possui rotinas que podem contribuir para a adoção de inovações.

Existem incentivos para se investir em inovação na educação, por exemplo: contribuição para a melhoria em aprendizagem e educação (MULGAN e ALBURY, 2003); e redução dos custos e aumento da eficiência (MULGAN e ALBURY, 2003).

Abramovay et al. (2003) consideram que a motivação e o comprometimento dos membros são valiosos para solucionar problemas em escolas públicas brasileiras inovadoras. 
A inovação pode ser caracterizada através de três abordagens: considerando o ser humano como agente inovador; considerando a estrutura organizacional; e, através de uma terceira abordagem que abrange as duas vertentes, atendendo mais rapidamente às questões sobre inovação (MACHADO et al., 2012). Como resultados dessa interação, têm-se a cultura e o clima organizacionais, considerados fatores significativos para o direcionamento à inovação (VAN DE VEN, 1986) e que serão analisados na próxima subseção.

\subsection{Cultura e clima organizacionais}

Observa-se que as inovações organizacionais podem influenciar a cultura de uma instituição (MACHADO et al., 2012). De acordo com Fleury (1987), alguns autores consideram a cultura uma variável interna, mas também há aqueles que ponderam sobre uma variável independente da organização, pois a cultura da sociedade é trazida por seus membros para dentro e se internaliza.

Conforme Schein (1986), há uma lista de categorias que podem auxiliar a investigação da cultura na organização. Assim, a interação entre os membros deve ser analisada, bem como estudada a história da organização e os incidentes críticos responsáveis pela formação da cultura. A partir de sua identificação, o autor sugere que seja estudada cada situação, com envolvimento dos próprios membros, recuperando seu ponto de vista e avaliando os resultados, além de envolvê-los nas descobertas das entrevistas.

O clima organizacional está relacionado à interação entre a própria organização, os indivíduos e seu ambiente; e sua percepção pode variar de acordo com os níveis hierárquicos de quem avalia (PAYNE e MANSFIELD, 1973).

Berman e Kim (2010) reconhecem a importância da criatividade para o clima em um ambiente de trabalho. Assim sendo, o tema será aprofundado a seguir.

\subsection{Cultura e clima $O=$ organizacional de $S=$ suporte à criatividade e inovação}

A qualidade dos serviços oferecidos pelos membros de uma organização está relacionada ao apoio na geração e no acolhimento de ideias, caracterizando uma competência administrativa que contribui para uma cultura de aprendizagem (Penrose, 2006).

Conforme Kanter (1983), a organização que possui ambiente voltado para a criatividade se apresenta como flexível e é caracterizada por se adaptar continuamente às mudanças, além disso, promove a autonomia de seus membros em busca de soluções para os problemas (AMABILE e GITOMER, 1984). Contudo a padronização de práticas e regulamentos rigorosos institucionais limita a participação do indivíduo nas decisões e freia grandes mudanças contributivas no ambiente organizacional (GILES e HARGREAVES, 2006).

Kim e Yoon (2015) destacam que as pesquisas entre o clima orientado para a criatividade e a cultura organizacional direcionada para a inovação no setor público são pouco exploradas e necessitam de mais investigação. O desempenho criativo pode sofrer interferência positiva através do foco, espírito de equipe e comunicação, bem como interferência negativa por meio de uma estrutura organizacional burocrática (AKDOGAN e KALE, 2017).

O ambiente de trabalho é um fator importante para a criatividade e inovação organizacional (AMABILE, 1997). Alguns autores evidenciam a diferença entre criatividade e inovação, tais como Volpp et al. (2017). Segundo a autora, o ambiente de trabalho deve ser composto principalmente por motivação organizacional, recursos financeiros, recursos de pessoas e disponibilidade de tempo e liderança que estimule a inovação. Dessa forma, realiza-se uma representação de Amabile (1997) do impacto do ambiente na criatividade (Figura 1). 

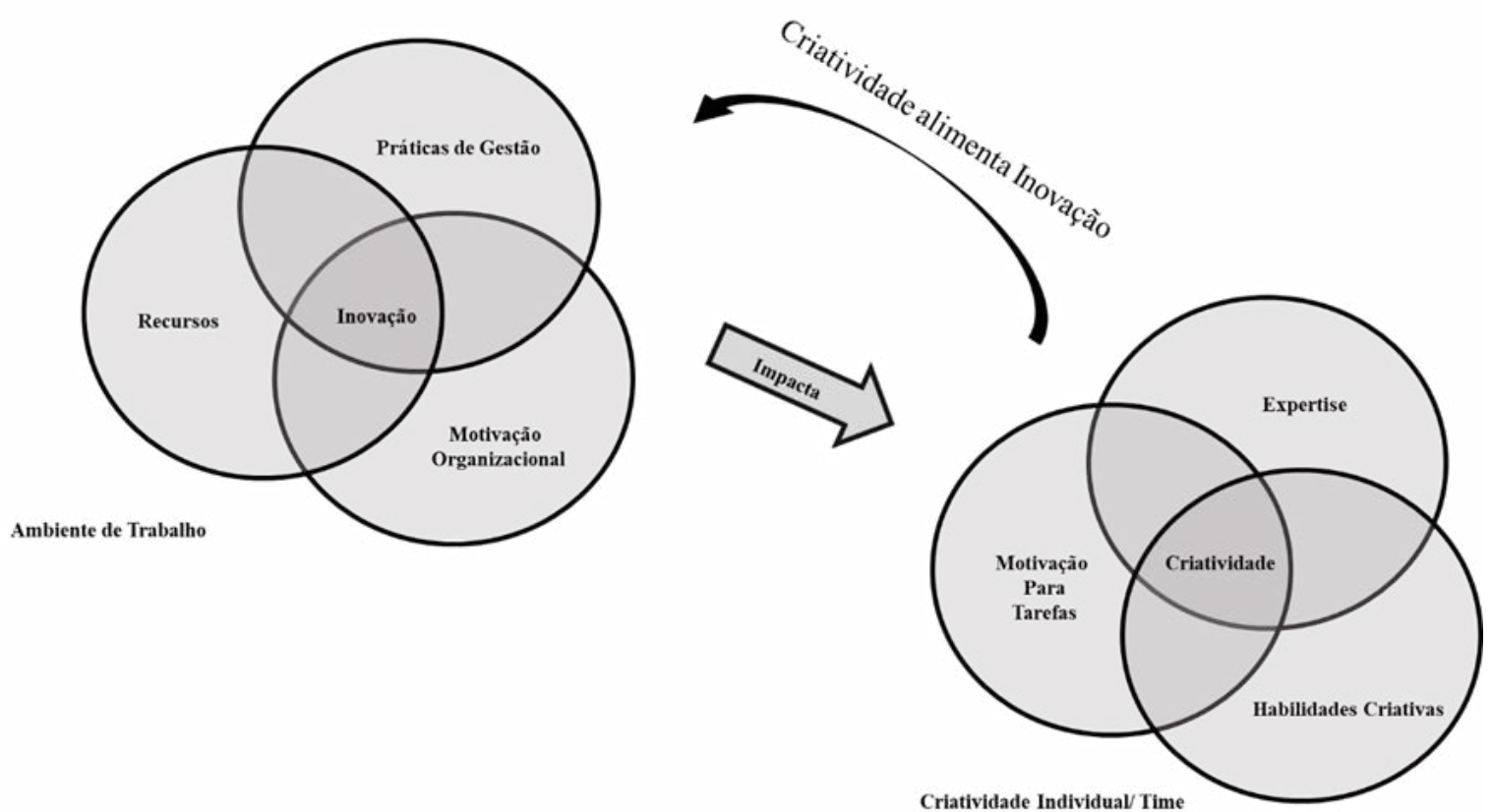

Figura 1. Impacto do ambiente organizacional na criatividade

Fonte: Adaptado de Amabile (1997)

Segundo Siegel e Kaemmerer (1978), a organização inovadora tem como característica principal a promoção da criatividade de seus membros. Assim, relacionam suas dimensões e sugerem uma escala para auxiliar a análise do clima organizacional, conforme descrito a seguir.

\subsection{Escala Siegel}

Siegel e Kaemmerer (1978) apresentam, inicialmente, cinco dimensões reportadas a uma organização inovadora: liderança, posse, normas para a diversidade, desenvolvimento contínuo e consistência.

O perfil da liderança das organizações inovadoras é aquele que incentiva a criação de novas ideias e o desenvolvimento pessoal de cada indivíduo, enquanto o sentimento de posse ocorre quando os membros das organizações aplicam novas ideias e percebem que se envolvem nos processos, sentindo-se responsáveis pela tomada de decisão.

As normas para diversidade simbolizam a forma colaborativa com que os integrantes atuam perante as diversidades dentro da organização, contribuindo para a criatividade do sistema. Por sua vez, o desenvolvimento contínuo é caracterizado pelo processo contínuo de mudança, perfil das organizações inovadoras, que permitem novas abordagens para a solução de problemas.

A consistência é importante por afirmar a coerência lógica da constituição das ideias, que podem produzir "consequências imediatas e não-intencionais, que podem entrar em conflito com o objetivo da atividade" (SIEGEL e KAEMMERER, 1978, p. 555).

Siegel e Kaemmerer (1978) verificam três fatores, após análise fatorial, para caracterizar e distinguir os diferentes tipos de climas que contribuem para a inovação das organizações tradicionais: suporte da criatividade, tolerância das diferenças e compromisso pessoal.

No primeiro fator, suporte da criatividade, os membros contribuem para a gestão, através de novas ideias, com a organização disponível para mudanças, ressaltando-se a liderança como peça fundamental nesse novo processo. No segundo fator, a tolerância das diferenças, a organização demonstra tolerância às diferenças entre seus membros, sem que barreiras sejam impostas. Por último, o compromisso pessoal está relacionado diretamente à sensação de propriedade provocada pelo compromisso e envolvimento do indivíduo.

Em se tratando do suporte à criatividade, Toda (2015) corrobora a visão dos autores ao enfatizar que existe influência do líder sobre o clima organizacional, especificamente voltado para o fomento da criatividade 
e da inovação. Em pesquisa realizada por ele, o autor apresenta relação significativamente positiva entre a liderança transformacional e os membros docentes, contribuindo para o desenvolvimento dos processos da organização.

Siegel e Kaemmerer (1978) elaboraram um questionário que contribuiu, a partir dos resultados de sua aplicação, para detectar o nível de apoio à inovação de uma organização e para medir suas dimensões. Esse questionário é valido e confiável, podendo ser utilizado em estudos posteriores na área, tanto entre unidades em uma mesma organização quanto uma mesma unidade ao longo dos anos, entre outros. $O$ instrumento elaborado foi baseado nos fatores da escala Siegel de apoio à inovação (Siegel Scale of Support for Innovation - SSSI), que auxiliam na análise do clima organizacional.

\section{Metodologia da pesquisa}

O clima organizacional pode ser medido através de diversas escalas. Climate Creative Questionnaire (CCQ) possui dez dimensões de apoio ao clima criativo (Lauer, 1994). Outra escala, Assessing the Climate for Creativity (KEYS), avalia a criatividade em ambientes organizacionais (Amabile, et al., 1996). Team Climate Inventory (TCI) mensura o clima para a inovação dos processos em grupo (Anderson and West, 1996). A Siegel Scale of Support for Innovation (SSSI) apresenta três fatores para caracterizar e distinguir os diferentes tipos de climas que contribuem para a inovação das organizações tradicionais (Siegel e Kaemmerer, 1978).

A escala Siegel foi utilizada como ferramenta em estudos anteriores relacionados à avaliação do clima de suporte à criatividade e inovação em instituições de ensino (Toda et al, 2015; Toda, 2013; Almeida et al, 2016).

Adotou-se o instrumento SSSI de Siegel e Kaemmerer (1978) para avaliar o clima organizacional de suporte à criatividade e inovação porque foi considerado adequado para o estudo, visto que os seus autores o utilizaram para teste em um ambiente educacional, mesmo contexto que este trabalho explora. A crítica de pesquisadores quanto ao uso dessa escala (Amabile et. al, 1996; Mathisen e Einarsen, 2004) recai por não ter sido utilizada em ambientes de negócios, para os quais não foi validada estatisticamente.

Em razão dos autores considerarem que a escala Siegel apresenta uma amplitude de temas e subtemas significativos, abrangendo teoricamente o assunto do clima organizacional, essa escala foi adotada como roteiro. O questionamento inicial sobre a avaliação dos temas em escala Likert foi proposital para que pudesse apenas introduzir o respondente para uma discussão aprofundada sobre os temas, procurando os porquês das respostas e capturando sentimentos e significado das falas.

Os programas de pós-graduação foram selecionados a partir de uma mesma instituição de pesquisa no estado do Rio de Janeiro, objetivando manter uma aproximação da cultura organizacional esperada entre eles. Mesmo com perfis diferentes dentro de cada unidade, a escolha das organizações implicava a submissão às mesmas regulamentações e órgãos, o que facilitaria a análise do clima organizacional.

Foram avaliados dois programas com cursos de mestrado e doutorado de uma instituição de ciência e tecnologia em saúde - a Fiocruz. Um programa de nota 7 (sete), em ambos os cursos de uma unidade, e um programa de nota 3 (três) em mestrado e 2 (dois) em doutorado, de outra unidade, de acordo com a avaliação provisória do último quadriênio (2013-2016).

Foi adotada uma estratégia qualitativa que permitiu obter conhecimento sobre o clima de suporte à criatividade e inovação, e levantar a realidade do preenchimento para avaliação da Capes, contribuindo para que o pesquisador desenvolvesse uma análise a partir dos dados obtidos (ROESCH, 1999).

Houve observação prévia do comportamento dos programas de pós-graduação para apropriar-se dos procedimentos para submissão das informações para a avaliação da Capes. Sendo possível, dessa forma, determinar os sujeitos diretamente envolvidos: em geral, representados pela coordenação, que possui o poder de decisão, além de secretários, responsáveis pelo suporte à coordenação, e docentes.

Assim, foram selecionados para as entrevistas dentro de cada programa: o coordenador, o secretário, um docente permanente membro da Comissão de Pós-graduação (CPG - que atua contribuindo para as decisões coletivas no programa), um docente permanente não membro da CPG, e um docente colaborador 
com baixo impacto na avaliação do programa. A distribuição das entrevistas realizadas encontra-se explicitada conforme a Tabela 1.

Tabela 1: Relação entre sujeitos e entrevistas realizadas

\begin{tabular}{llcc}
\hline Programa & Sujeito & Código & $\begin{array}{c}\text { Tempo da Entrevista (em } \\
\text { minutos) }\end{array}$ \\
\hline P7 (Programa nota 7) & Coordenador do programa & C7 & 63 \\
\hline P7 & Docente permanente - integrante da CPG & DPI7 & 57 \\
\hline P7 & Docente permanente - não integrante da CPG & DPNI7 & 46 \\
\hline P7 & Docente colaborador & DC7 & 37 \\
\hline P7 & Secretária acadêmica & SA7 & 42 \\
\hline P3 (Programa nota 3) & Coordenador do programa & C3 & 69 \\
\hline P3 & Docente permanente - integrante da CPG & DPI3 & 97 \\
\hline P3 & Docente permanente - não integrante da CPG & DPNI3 & 67 \\
\hline P3 & Docente colaborador & DC3 & 61 \\
\hline P3 & Secretária acadêmica & SA3 & 70 \\
\hline
\end{tabular}

Fonte: Elaboração própria.

Inicialmente, foi realizado um teste com o coordenador de um terceiro programa da instituição a fim de validar o roteiro para essa pesquisa. O teste permitiu apreciar o comportamento do entrevistado frente ao esclarecimento de algumas afirmações e redundâncias, além da predisposição para contribuir frente a um roteiro de 61 afirmações, o que possibilitou ajustes visando adequação.

Entre outubro e novembro de 2017, fez-se a aplicação de entrevistas em profundidade com o uso da escala Siegel como roteiro com os sujeitos. Alguns trechos do roteiro submetido são demonstrados a seguir:

\section{Primeiro fator - Suporte da criatividade}

S1: Este departamento está sempre buscando desenvolver novas soluções.

S2: É flexível e está sempre se adaptando a mudanças.

S3: A direção deste departamento respeita nossa criatividade.

S4: Aqui, no departamento, há liberdade para que as pessoas resolvam o mesmo problema de formas diferentes.

S5: A criatividade é incentivada aqui.

S6: O comportamento da direção do departamento pode ser descrito como de dar apoio aos professores.

S7: Aqui, às vezes, paramos para reexaminar nossas crenças mais básicas.

\section{Segundo fator - Tolerância das diferenças}

S1: Eu participo das decisões que são tomadas aqui.

S2: As pessoas aqui falam muito, mas não fazem o que pregam.

S3: Neste departamento, esperam que as pessoas lidem com os problemas sempre da mesma forma.

S4: As pessoas que ocupam os cargos-chave no departamento obtêm o crédito pelas ideias dos outros.

S5: Há gente aqui que passa o tempo dizendo aos outros o que fazer.

S6: Às vezes, a forma como as coisas são feitas pioram a situação.

S7: As pessoas que dirigem o departamento falam que se deve agir de um jeito, e agem de outro.

\section{Terceiro Fator - Compromisso pessoal}

S1: Eu consigo me identificar com as ideias com as quais eu trabalho aqui.

S2: Eu realmente não me importo com o que acontece a este departamento.

S3: Eu estou comprometido (a) com os objetivos do departamento. 
S4: Meus objetivos pessoais e as metas desta organização são bastante semelhantes.

S5: As pessoas que trabalham neste departamento preferem trabalhar aqui a em qualquer outro lugar.

S6: De forma geral, eu tenho um senso de comprometimento com este departamento.

S7: As pessoas aqui são muito leais ao departamento.

Realizaram-se anotações durante as entrevistas, que permitiram uma observação atenta às respostas de cada indivíduo. As 61 afirmações foram organizadas pelos fatores da escala, formando três grupos a serem avaliados de cada programa individualmente e, após, comparativamente: suporte à criatividade, tolerância às diferenças e compromisso pessoal.

Como técnica de análise dos dados, foi realizada análise de conteúdo, que permitiu compreender a perspectiva dos membros envolvidos nos cursos da pesquisa para tornar a gestão acadêmica eficaz (ROESCH, 1999).

Em sequência, foram dispostas as fichas de avaliação dos programas provisórias do último quadriênio (2013-2016), que permitiram a triangulação dos dados obtidos.

\section{Resultados}

Algumas características dos programas se apresentaram relevantes para análise. A criação do P7 ocorreu em 1989, enquanto o P3 ocorreu apenas em 2011. O P3, além de ensino e pesquisa (P7), possui assistência como área de atuação e o preenchimento da plataforma para avaliação do programa é realizado por um bolsista contratado especificamente para esse fim, enquanto no P7 é feito por um secretário que integra a equipe de composição do programa.

Os resultados foram, inicialmente, estruturados por programa e por fatores da escala Siegel. Em seguida, realizou-se a análise comparativa entre as considerações dos entrevistados. Oportunamente, disponibilizou-se o quadro relacionando os itens e a avaliação de cada programa, conforme disposto a seguir.

\subsection{Suporte à criatividade}

Comparando-se o programa de nota máxima com o programa de nota limite mínima para credenciamento (regular), observa-se que a busca de novas soluções no P7 é marcada pela geração de conhecimento e adequação dos processos, enquanto o P3 ainda é considerado novo, em desenvolvimento e sobrecarregado com tarefas além da PG.

Outra questão interessante notada é que, enquanto em um programa a criatividade é estimulada e ganha destaque pela coordenação (P7), no outro, esse incentivo é colocado em questão (P3). Todavia considera-se que, tanto no P7 quanto no P3, a liderança é reconhecida como apoiadora dos membros. No $\mathrm{P} 3$, nota-se certo desconforto frente à alocação de recursos humanos e sobrecarga de tarefas, principalmente relacionada à assistência, o que pode influenciar a corresponsabilidade e acarretar o comprometimento difuso da equipe.

Os métodos utilizados pelo P7 estão adequados aos seus objetivos e em consonância com os critérios exigidos pela Capes. O P3 alerta sobre a necessidade de mais foco e evidência das metas. Segundo os entrevistados, a assistência às novas ideias, mesmo considerando interferências externas, está disponível, contudo observa-se que o P3 se apresenta como mais conservador e possui tendência a reproduzir ideias.

Com relação ao recebimento de novas ideias, o P7, diferente do P3, considera que são avaliados da mesma forma, independente do indivíduo e de acordo com os objetivos e recursos da PG. O integrante DC7 ressalta: "De uma forma geral, tende à adesão. Todos os colaboradores e docentes que entram no programa querem aderir. Raramente a gente quer contestar o que já está lá dentro".

O P7 acredita que, quando um novo problema surge, apesar da frustração, ele é manuseado de uma forma construtiva, o que não é percebido em todos os momentos no P3. Essa análise confirma a explicação de Sternberg e Lubert (1991), que destacam a relevância de combinação entre processos, conhecimento, estilo intelectual, personalidade, motivação e ambiente. P7 reconhece estar no caminho certo, independentemente 
de aceitar ou não os critérios e as exigências da Capes. A confiança é marcada pelo acompanhamento próximo da equipe. O P3 se vê dividido entre o que é contributivo para a PG e o que precisa ser mudado, incluindo a alocação dos recursos humanos.

Dentre as características observadas, destacamos abaixo (Tabela 2) as mais relevantes:

Tabela 2: Quadro comparativo das características mais relevantes quanto ao suporte à criatividade

\begin{tabular}{l|l|l}
\hline SUPORTE À CRIATIVIDADE & $\mathbf{P 7}$ & P3 \\
\hline $\begin{array}{l}\text { Reconhecimento de incentivo } \\
\text { à criatividade }\end{array}$ & $\begin{array}{l}\text { A criatividade é estimulada pela } \\
\text { coordenação. }\end{array}$ & $\begin{array}{l}\text { Alguns membros questionam a } \\
\text { existência de incentivo pela gestão do } \\
\text { programa. }\end{array}$ \\
\hline $\begin{array}{l}\text { Métodos de acordo com os } \\
\text { objetivos }\end{array}$ & $\begin{array}{l}\text { Orientados rigorosamente pelos } \\
\text { critérios de avaliação da Capes. }\end{array}$ & $\begin{array}{l}\text { Por veze, o programa opta por } \\
\text { se basear em seus princípios } \\
\text { qualitativos, e não nos da Capes. }\end{array}$ \\
\hline $\begin{array}{l}\text { Abertos e receptivos a } \\
\text { mudanças }\end{array}$ & $\begin{array}{l}\text { Sim, mas encaram os critérios } \\
\text { Capes como limitação. }\end{array}$ & $\begin{array}{l}\text { Sim, mas encara o fato de ser um } \\
\text { programa novo como barreira, sem } \\
\text { histórico, tende a reproduzir as ideias. }\end{array}$ \\
\hline $\begin{array}{l}\text { Apoio da coordenação ao } \\
\text { desenvolvimento individual }\end{array}$ & $\begin{array}{l}\text { Realizado através de planilhas de } \\
\text { acompanhamento próprio para } \\
\text { feedback. }\end{array}$ & $\begin{array}{l}\text { A coordenação percebe o fator } \\
\text { tempo como um obstáculo para } \\
\text { acompanhamento das produções. }\end{array}$ \\
\hline
\end{tabular}

Nota. Tabela elaborada pelos autores.

\subsection{Tolerâncias às diferenças}

Destaque é dado à atenção do P7 para que os problemas sejam resolvidos. Em geral, os problemas são avaliados particularmente e a solução, considerando experiências anteriores, pode variar de acordo com cada caso. Como mencionado por Amabile e Pillemer (2012), cada estágio do processo de criação de ideias é importante para a solução de problemas.

No P3, foi possível concluir que, independentemente da forma, as pessoas devem ser flexíveis e os critérios utilizados para solução dos problemas devem ser claros, a fim de que haja espaço para argumentos de quem discorde. Foram citadas a possibilidade de ausência de organização interna, a falta de memória e a continuidade na sequência dos processos, visando a otimização na solução dos problemas. Do mesmo modo, Siegel e Kaemmerer (1978) acrescentam que o desenvolvimento contínuo é caracterizado pelo processo de contínuo de mudança, perfil das organizações inovadoras, que, por sua vez, permitem novas abordagens para a solução de problemas.

No P7, não se reconhece que as pessoas que ocupam cargos-chave obtêm créditos pelas ideias dos outros, com exceção das orientações para atender a um dos critérios da Capes. Com opiniões divididas, não foi possível determinar o mesmo no P3. O docente DPI3 destaca: "Assim, fracasso ou êxito, ele é dividido, só que a gente tende, quando é êxito, todo mundo quer, quando é fracasso, a gente quer arrumar culpado...". Schein (1988) assegura que, na falta de integração interna ou outros fatores culturais que possam vir a interferir na sobrevivência da equipe, é necessária a atuação do líder como última instância.

A maneira de agir, apesar de ser um trabalho coletivo, pode implicar possíveis falhas para o P7, enquanto para o P3 considera que a flexibilidade em muitas questões reflete em descontrole operacional. No que tange o uso de métodos testados e aprovados, o P7 afirma utilizar-se, bem como busca melhorar e inovar os processos. Os entrevistados do P3 se dividem entre a tradição e a inovação. De um lado, refletese sobre uma tendência à reprodução e ao conservadorismo, apesar de demonstrar interesse na inovação com o passar do tempo. E, na mesma vertente, destaca-se mais uma vez o engessamento consequente dos critérios de avaliação da Capes. Os entrevistados acreditam ter a oportunidade de testar suas próprias ideias, mas no P3 direcionam a uma forma individual, de cunho do pesquisador, e nem tanto a uma forma coletiva no programa.

Dessa forma, identifica-se similaridade com a teoria apresentada por Ruvio et al. (2014), que asseguram a abertura organizacional através da receptividade a novas ideias e mudanças pelos seus membros, 
mensurando a adesão à inovação pela organização. Observou-se que a maioria acredita que ideias originais e maneiras criativas são respeitadas pela coordenação de seus respectivos programas. Inclusive, um dos docentes do P7 destacou que suas ideias sempre foram encorajadas e valorizadas. De maneira oposta, DC3 acredita que alguns não participam tanto do processo para contribuir com as ideias.

No P7, considera-se que as soluções para os problemas podem variar de acordo com a mudança do cenário, buscando-se seguir certa sistemática e avaliando as soluções anteriormente aplicadas. O P3 reconhece essa tendência, mas ressaltam que as soluções não são continuadas e que esse problema é uma das discussões atuais do programa, pois buscam estimular a manutenção das questões mais importantes. Conforme Abramovay et al. (2003), a motivação e o comprometimento dos membros são valiosos para solucionar problemas.

Dentre as características observadas, destacamos abaixo (Tabela 3) as mais relevantes:

Tabela 3: Quadro comparativo das características mais relevantes quanto à tolerância às diferenças

\begin{tabular}{l|l|l}
\hline TOLERÂNCIA ÀS DIFERENÇAS & P7 & P3 \\
\hline $\begin{array}{l}\text { Forma de encarar os } \\
\text { problemas }\end{array}$ & $\begin{array}{l}\text { Consideram experiências } \\
\text { anteriores, objetivando soluções } \\
\text { eficazes. }\end{array}$ & $\begin{array}{l}\text { Consideram que os critérios } \\
\text { utilizados em busca de solução } \\
\text { devem ser mais claros e definidos. }\end{array}$ \\
\hline $\begin{array}{l}\text { Maneira como agem pode } \\
\text { piorar uma situação }\end{array}$ & $\begin{array}{l}\text { O trabalho é realizado de forma } \\
\text { coletiva, mas reconhecem } \\
\text { possíveis falhas. }\end{array}$ & $\begin{array}{l}\text { Frequentemente, pois existe } \\
\text { flexibilidade em muitas questões } \\
\text { decisivas. }\end{array}$ \\
\hline Flexibilidade para mudanças & $\begin{array}{l}\text { Observação mais restrita dos } \\
\text { critérios Capes. }\end{array}$ & $\begin{array}{l}\text { Existe certa liberdade, pois não se } \\
\text { restringem aos critérios Capes. }\end{array}$ \\
\hline
\end{tabular}

Nota. Tabela elaborada pelos autores.

\subsection{Compromisso pessoal}

Analisando o compromisso pessoal, baseado em Siegel e Kaemmerer (1978), que verificam esse aspecto relacionado diretamente à sensação de propriedade provocada pelo compromisso e envolvimento do indivíduo, evidenciou-se que todos os entrevistados se identificam com as ideias com as quais trabalham. Eles completam que há uma sequência admirável decorrente da maior fluidez e oportunidades, configurando um dos principais fatores de sucesso. Contudo são feitas ressalvas quanto ao fator de impacto da quantidade de produção pela Capes, desvalorizando o aprofundamento da qualidade, o que direciona as metas do pesquisador para outro caminho. Em uma análise pessoal de um dos entrevistados do P3, observou-se uma necessidade de ampliação do conhecimento dentro da PG, que o faz questionar essa identidade.

Ao se analisar os objetivos pessoais e as metas da organização do P7, observam-se resultados bastante semelhantes e condizentes com os critérios de avaliação da Capes. Afinal, a Capes fornece bolsas de produtividade, insumos para os laboratórios e recursos para a pesquisa evoluir como um todo, afirma DC7. Apesar disso, os docentes do P7 se mostraram interessados em fazer diferente, realizar pesquisas com mais tranquilidade e sem se preocupar tanto com a quantidade da produção. No P3, nem todos os profissionais se sentem seguros em afirmar que seus objetivos pessoais e metas do programa sejam semelhantes. Alguns afirmam sentir a necessidade de que haja uma discussão mais clara sobre o tema, tornando-os mais explícitos. Outro destaque feito é o de que o programa possui pessoas e perfis profissionais muito distintos, o que pode dificultar a definição desses objetivos.

Apesar de alguns não enxergarem uma relação negativa no $\mathrm{P} 3$, a maioria acredita que seja algo recíproco entre a instituição e o indivíduo e que esses sejam leais aos seus próprios objetivos, e não à PG. Além disso, é possível concluir que todos os entrevistados declararam um verdadeiro senso de responsabilidade pelo trabalho. Nota-se que DPI3 considera que existem dois perfis de docentes, aqueles que se interessam, que são leais ultrapassam horas em dedicação, e aqueles que são passivos, ou indagam o trabalho do coletivo para que possam produzir também. O coordenador $\mathrm{C} 3$ reconhece que, muitas das vezes, atua em resposta à confiança depositada e demandada pelos membros da equipe. 
As respostas estão em consonância ao estudo de Cooper-Hakim e Viswesvaran (2005), no que diz respeito ao comprometimento profissional, dedicação e responsabilidade no trabalho, sendo que os referidos autores devem ser reconhecidos quanto aos sentimentos positivos prestados no cargo.

Dentre as características observadas, destacamos a seguir (Tabela 4) as mais relevantes:

Tabela 4: Quadro comparativo das características mais relevantes quanto ao compromisso pessoal

\begin{tabular}{l|l|l}
\hline \multicolumn{1}{c|}{ COMPROMISSO PESSOAL } & \multicolumn{1}{c}{ P7 } & \multicolumn{1}{c}{ P3 } \\
\hline Identificação com as ideias & $\begin{array}{l}\text { Os membros se adaptam aos } \\
\text { critérios Capes. }\end{array}$ & $\begin{array}{l}\text { Há necessidade de ampliação do } \\
\text { conhecimento dos critérios Capes. }\end{array}$ \\
\hline Lealdade ao programa & $\begin{array}{l}\text { Existência de interesses mútuos } \\
\text { entre o indivíduo e a PG. }\end{array}$ & $\begin{array}{l}\text { Os docentes são leais aos próprios } \\
\text { objetivos individuais. }\end{array}$ \\
\hline Senso de comprometimento & $\begin{array}{l}\text { Existe um acompanhamento } \\
\text { pessoal da produção. }\end{array}$ & $\begin{array}{l}\text { Dependente do vínculo de categoria } \\
\text { do docente com o programa. }\end{array}$ \\
\hline
\end{tabular}

Nota. Tabela elaborada pelos autores.

\section{Discussão}

Inicialmente, a realização desta pesquisa visava à identificação de boas práticas de programas qualificados com notas sete, aplicadas ao preenchimento da plataforma de avaliação da Capes. A partir do aprofundamento do referencial teórico, notou-se a necessidade de se estudar o clima organizacional orientado para a criatividade e a inovação desses programas, comparando os de nota mais alta aos de nota mais baixa.

Destacam-se, na tabela 5, características peculiares dos programas pesquisados que, no decorrer das entrevistas, apresentaram-se como relevantes para a análise:

Tabela 5: Quadro comparativo das características relevantes para análise de cada programa

\begin{tabular}{l|c|c}
\hline CARACTERÍSTICAS PECULIARES OBSERVADAS & P7 & P3 \\
\hline Criação do programa & 1989 & 2011 \\
\hline Áreas de atuação & Ensino e pesquisa & Ensino, pesquisa e assistência \\
\hline Preenchimento da plataforma & Secretário do programa & Bolsista contratado \\
\hline
\end{tabular}

Nota. Tabela elaborada pelos autores.

O programa mais bem avaliado é voltado para a área de Ensino e pesquisa, enquanto o $P 3$, mesmo que não seja a natureza de todos os docentes que o compõem, se divide entre Ensino, pesquisa e assistência.

Nesse sentido, observou-se que essa variedade de áreas pode gerar outros problemas, como indevida alocação de recursos humanos e sobrecarga de atribuições, que influenciam a corresponsabilidade, a proatividade e o comprometimento no cumprimento das metas e tarefas.

Outra variedade relevante foi a quantidade de docentes que compõem cada PG. O programa com nota máxima (P7) foi representado pelo dobro de indivíduos em acompanhamento.

É válido ressalvar que ambos os programas possuem uma Comissão de Pós-Graduação (CPG) eleita periodicamente, que contribui para a orientação e a coordenação das atividades do curso e seu desenvolvimento; a definição de processo e critérios para credenciamento dos docentes; a delegação de gestão de processos regulares internos; o acompanhamento e a avaliação de pesquisa e produção do curso; e a resolução de problemas mais críticos.

Observou-se no P7 um acompanhamento mais próximo da coordenação e membros da CPG dos processos e produção dos docentes, diferente do perfil de liderança identificado no programa com nota três (P3). No mesmo programa, notou-se uma homogeneidade e coerência entre as respostas, que permitiu atestar certo entrosamento entre as pessoas, o que denota uma cultura mais transparente e um clima mais favorável. 
O P3 é relativamente novo, criado desde 2011, tendo feedback da Capes apenas nos relatórios dos quadriênios disponibilizados em 2013 e 2017; principalmente quando comparado ao P7, um programa mais consolidado, o que pode justificar alguns desalinhamentos.

O P7 parece estar continuamente se adaptando às mudanças, considerando como base os critérios pré-estabelecidos pela Capes e pela organização. Enquanto o P3, por não se sentir consolidado, ainda se apresenta um pouco conservador e em fase de adaptação à novidade, apesar de demonstrar interesse em inovação.

Por essa ausência de solidez até o momento, o programa se mostrou mais flexível e a percepção dos entrevistados foi que esse fato pode ter prejudicado a avaliação no último quadriênio. Foram considerados, por esse ângulo, falta de organização interna, objetivos bem definidos e descontinuidade nos processos.

Ambos questionaram alguns critérios exigidos pela Capes que, de certa forma, reconhecem impactar na qualidade do produto e assumem adaptar muitas informações somente para atender a essas exigências.

Em suas proporções, recebem benefícios da Capes, como bolsas de pesquisa e produtividade, insumos para os laboratórios e apoio para que a pós-graduação possa evoluir como um todo, mas, ainda assim, sentem-se com recursos limitados para maiores avanços.

Essa limitação de recursos contribuiu para mobilização de alguns docentes à procura de atuação complementar em outros programas de PG, em busca de mais estrutura e flexibilidade, o que pode impactar, em tese, no direcionamento da sua linha de pesquisa.

O perfil e a lealdade do corpo docente no P7 são marcantes, enquanto o P3 possui um perfil mais heterogêneo, alguns cujo interesse é maior e possuem mais lealdade, enquanto outros possuem características mais passivas.

Ambos os programas reconhecem o respeito à criatividade pela liderança, que também é marcado pelo acompanhamento mais próximo dessa coordenação. Mas, no P3, a capacidade de criação pode ser mais ampla do que é percebida pelo líder e o acompanhamento não se apresenta tão próximo, justificado pelas atribuições desse coordenador.

Ambas as secretarias acadêmicas se envolvem com intensidade no processo de avaliação da PG, mas cabe ressaltar que o suporte no P7 é realizado por uma secretaria exclusiva, enquanto no P3 o secretário possui outras atividades, e não é o mesmo responsável por encaminhar as informações do programa à Capes, podendo interferir na qualidade da coleta.

Uma das limitações é a generalização dos resultados obtidos, pois se trata de resultados de dois programas de uma mesma instituição, o que não garante que sejam observados em outros programas de pós-graduação ou outras instituições.

No geral, em ambos foi demonstrada uma carga de emoção com a PG, desde a coordenação ao membro de secretaria acadêmica.

\section{Conclusão}

O estudo confirmou as teorias existentes, notando-se que o clima, orientado para criatividade e inovação, impactou a nota de avaliação dos programas perante a Capes. Foi observado o comportamento das dimensões apontadas por Siegel, constatado através do estudo e corroborado no parecer dos itens nas fichas de avaliação de cada programa na qualidade dos serviços caracterizada pela competência administrativa.

Mediantes os resultados apresentados, a pesquisa se apresentou relevante e útil para auxiliar a tomada de decisões dentro dos programas de pós-graduação stricto sensu. Aos coordenadores possibilita avaliar as oportunidades para ajuste ou desenvolvimento junto à equipe, referente à cultura e clima organizacionais a pequenos processos que podem vir a contribuir para ascensão da produção individual e coletiva, bem como à nota da avaliação do programa.

Por fim, sugere-se que, futuramente, o estudo seja ampliado para programas que possuam área de ensino, bem como de assistência, ponto observado como relevante na composição do clima, e a outros 
programas de pós-graduação, incluindo diversidade de outras instituições, para que se obtenha mais segurança e sejam apresentados resultados que possam ser replicados de uma forma mais abrangente.

\section{Referências}

ABRAMOVAY, M. et al. Escolas inovadoras: experiências bem-sucedidas em escolas públicas. Brasília: Unesco, 2003.

AKDOGAN, A.; KALE, E.. Impacts of internal factors in organizations on creative and innovative performance in hospitality companies. International Journal of Innovation Management, p. 1750049, 2017.

ALMEIDA, J. J. A., et al. Clima organizacional e a qualidade da vida acadêmica do estudante de ensino superior. Dissertação de Mestrado. UFRRJ. 2016.

AMABILE, T. M. Motivating creativity in organizations: On doing what you love and loving what you do. California Management Review, 40(1), 39-58, 1997.

AMABILE, T. M. et al. Assessing the work environment for creativity. Academy of management journal, v. 39, n. 5 , p. $1154-1184,1996$.

AMABILE, T. M.; GITOMER, J. Children's artistic creativity: Effects of choice in task materials.

Personality and Social Psychology Bulletin, 10, 209-215, 1984.

AMABILE, T. M.; PILLEMER, J. Perspectives on the social psychology of creativity. The Journal of Creative Behavior, v. 46, n. 1, p. 3-15, 2012.

AMARAL, R. M. et al. Ultrapassando as barreiras de conversão e tratamento de dados: indicadores de produção científica dos programas de pós-graduação em engenharia de materiais e metalúrgica. Em Questão, v. 23, n. 1, 2017.

ANDERSON, N.; WEST, M. A. The Team Climate Inventory: Development of the $\mathrm{TCl}$ and its applications in teambuilding for innovativeness. European Journal of work and organizational psychology, v. $5, n$. 1, p. 53-66, 1996.

BERMAN, E. M.; KIM, C. Creativity management in public organizations: Jumpstarting innovation. Public Performance e Management Review, 33, 619-652, 2010.

CAPES, Plataforma Sucupira. Disponível em: <http://sucupira.capes.gov.br/>. Acesso em: 29/07/2015

CAPES, Sobre a Avaliação. Disponível em <http://www.capes.gov.br/avaliacao/sobre-a-avaliacao>. Acesso em: 09 de maio de 2017

COOPER-HAKIM, A., e VISWESVARAN, C. The construct of work commitment: testing an integrative framework. Psychological Bulletin, v.131, n.2, 2005.

ESTEVÃO, C. V. Inovação e mudança nas organizações educativas públicas e privadas. Revista Portuguesa de Educação, [S. I.], v. 7, n. 1/2, p. 95-111, 1994.

FAGÁ, I. T.; QUONIAM, L. M. A relação entre produção científica e avaliação da Capes: um estudo cientométrico de um programa das Engenharias II e de um programa interdisciplinar. Revista Brasileira de Pós-Graduação, v. 12, n. 29, 2016.

FIDAN, T.; OZTÜRK, I.. The relationship of the creativity of public and private school teachers to their intrinsic motivation and the school climate for innovation. Procedia-Social and Behavioral Sciences, v. 195, p. 905-914, 2015.

FLEURY, M. T. L.. Estórias, mitos, heróis - cultura organizacional e relações de trabalho. RAE -Revista de administração de empresas. Rio de Janeiro, v.27, n.4, out./dez. 1987.

GILES, C.; HARGREAVES, A.. The Sustainability of Innovative Schools as Learning Organizations 
and Professional Learning Communities During Standardized Reform. Educational Administration Quarterly. 42 (1), 124-156, 2006.

HURLEY, R. F. Group culture and its effect on innovative productivity. Journal of Engineering and Technology Management, v. 12, n. 1-2, p. 57-75, 1995.

JUNIOR, H. A., et al. Estratégias acadêmicas e suas manifestações: o discurso e a prática. Revista Gestão Universitária na América Latina-GUAL, v. 4, n. 3, p. 126-152, 2011.

KANTER, R. M. The change masters. New York, NY: Simon e Schuster, 1983.

KIM, S.; YOON, G. An Innovation-Driven Culture in Local Government: Do Senior Manager's Transformational Leadership and the Climate for Creativity Matter?. Public Personnel Management, v. 44, n. 2, p. 147-168, 2015.

LAUER, K. J. The assessment of creative climate: An investigation of Ekvall's Creative Climate Questionnaire. Unpublished master's thesis, State University College, Buffalo, NY, 1994.

MACCARI, E. A. et al. Sistema de avaliação da pós-graduação da Capes: pesquisa-ação em um programa de pós-graduação em Administração. Revista Brasileira de Pós-Graduação, Brasília, v. 5, n. 9, 2008.

MACHADO, D. D. P. N., et al. Ambiente favorável ao desenvolvimento de inovações e cultura organizacional: integração de duas perspectivas de análise. Rev. Adm. (São Paulo) [online]. vol.47, n.4, pp.715-729. ISSN 1984-6142. http://dx.doi.org/10.5700/rausp1069, 2012.

MAYFIELD, M.; MAYFIELD, J. The effects of leader communication on worker innovation. American Business Review, v. 22, n. 2, p. 46, 2004.

MONTAGNER, M. A. et al. Scientific recognition in numbers: analysis of the profile of a vanguard from Lattes curricula vitae. Interface-Comunicação, Saúde, Educação, v. 13, n. 30, 2009.

MORO, A. B. et al. Fatores motivacionais e higiênicos considerados relevantes na visão dos docentes e discentes de programas de pós-graduação de uma instituição pública federal. Sociais e Humanas, Santa Maria, v. 26, n. 3, 2013.

MULGAN G. AND ALBURY D. Innovation in the Public Sector, Strategy Unit, Cabinet Office, London UK, 2003.

OECD. Measuring innovation in education and training. Discussion Paper n. 14. Paris: OECD, 2009.

PAYNE, R. L.; MANSFIELD, R. Relationships of perceptions of organizational climate to Organizational structure, context, and hierarchical position. Administrative Science Quarterly, 18, 515-526, 1973.

PENROSE, E. A teoria do crescimento da firma. Campinas: Ed. Unicamp, 2006.

ROESCH, S. M. A. Projetos de Estágios e de Pesquisa em Administração. São Paulo: Atlas, 2. ed, 1999. RUVIO, A. A., et al. Organizational Innovativeness: Construct Development and Cross-Cultural Validation. The Journal of Product Innovation Management, 31: 1004-1022, 2014.

SCHEIN, E. H. Organizational culture and leadership. San Francisco, Jossey Bass, 1986.

SCHEIN, E. H. Organizational culture. Sloan School of Management, 1988.

SIEGEL, S. M.; KAEMMERER, W. F. Measuring perceived support for innovation in organizations. Journal of Applied Psychology, 63(5), 553-562, 1978.

SOARES, S. A. S.; PAULY, E. L.. Profissionais em Gestão da Pós-Graduação: perfil, competências e atividades na percepção dos secretários dos programas de pós-graduação em Educação. Revista Brasileira de Pós-Graduação, v. 12, n. 28, 2015.

SOUZA, M. J.; GUIMARÃES, I. V. Histórias tecidas e publicizadas: formação, identidade e desenvolvimento profissional. Holos, v. 2, 2016. 
STERNBERG R., LUBART, T. An Investment Theory of Creativity and Its Development. Human Development, 34, 1-31, 1991.

TODA, F. A.; Um estudo sobre a influência da liderança sobre o clima organizacional de suporte à criatividade e inovação. Casi. Volta Redonda, RJ. 2015.

TODA, F., et al. Inovação em organizações de ensino: fatores contribuintes e desempenho. Revista de Administração FACES Journal, v. 14, n. 2, 2015.

TODA, F. A. Um Estudo sobre a Inovação nas Escolas Municipais da Cidade do Rio de Janeiro: Fatores Contribuintes e Relação com o Desempenho. Tese de Doutorado. PUC-Rio, 2013.

VAN DE VEN, A. H. Central problems in the management of innovation. Management Science, [S. I.], v. 32, n. 5, p. 590-607, 1986.

VOLPP, S., et al. Organizational climate relevant factors for creativity: case study in Brazilian firms.

Revista Ciencias Administrativas, v. 23, n. 1, p. 217-244, 2017.

Submetido em: $26 / 08 / 2018$

Aprovado em: 21/09/2019 